\title{
EFFECT OF WELDING REPAIRS ON THE QUALITY OF 304H STAINLESS STEEL WELDING JOINT
}

\section{A. NAIT SALAH \& M. KADDAMI}

Laboratory "Physical Chemistry of Processes and Materials" Faculty of Science and Technology, Hassan First University of Settat, Morocco

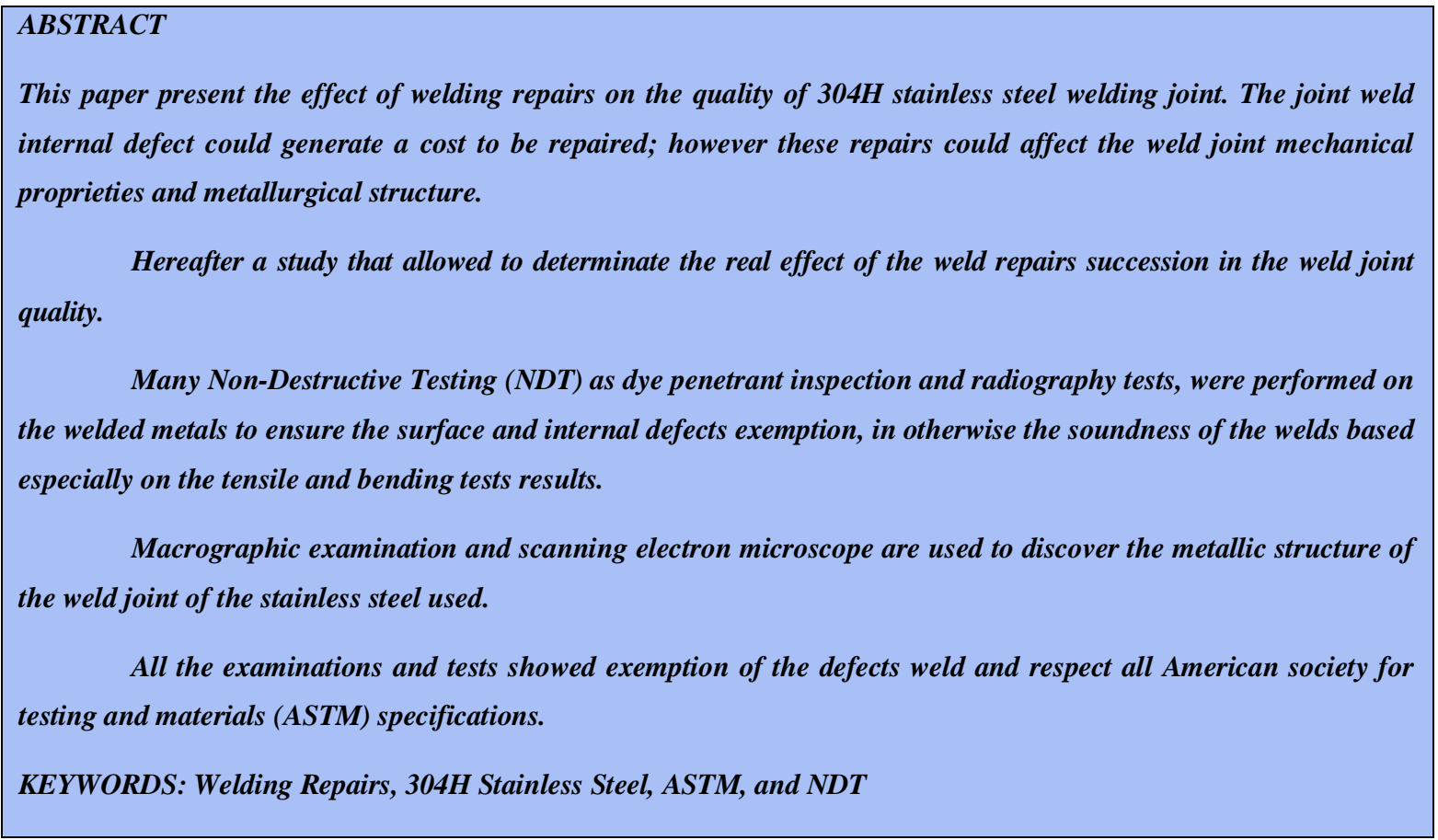

Received: May 13, 2020; Accepted: Jun 03, 2020; Published: Aug 03, 2020; Paper Id.: IJMPERDJUN2020573

\section{INTRODUCTION}

The pressure equipment industry is focusing on the quality and robustness of the equipment, so the area that can cause more problems is the weld joints. $304 \mathrm{H}$ stainless steel appears in the list of steam and acid pressure vessels.

Depending on the conditions of implementation of these welds on site or in workshop can cause welding defects. Unacceptable internal defects can be repaired and restored a second time, so as not to lose material from the sheet metal, tube or accessories.

By answering to the question that by Redoing the weld, its quality and resistance will be deteriorated. We will perform specimen to determine the effect of the repair on the strength and quality of the welds of the pressure vessels.

For this reason, we prepared three specimens, the first specimen welded without repair, the second sample welded after one repairs and the third specimen prepared with two repairs. Each repair carried out respects the preparation, cleaning and welding procedure.

The objective of using non-destructive testing methods, to ensure exemption from unacceptable defects. The methods used are visual, penetrant testing and X-ray inspection. 
After verifying the absence of defects, we proceeded to mechanical tests to verify the mechanical resistance of the specimens after the completion of the first and second repairs.

The bending test, tensile test and macrographic analysis were carried out in the three specimen to compare them with the standard in force.

In order to have the transformation and the change of the grains in three welding zones, we considered the control by scanning electron microscopy (SEM).

\section{MATERIALS AND METHODS}

\subsection{Specimen Preparation}

The three specimens are welded in the same conditions, are shown in Fig.1. The first specimen used after the welding.

The second specimen welded and the joint have been grinded until the edges. These edges will reconstitute a chamfer using the grinding. The bottom remains accessible to the electrodes used as it was originally. Then the joint will be rewelded.

The third spacemen will receive the repairs twice (three welds), the specimens are shown in Table 1[1].

The thickness of the sheet used for the preparation is $10 \mathrm{~mm}$, the welding angle is $60^{\circ} \pm 5^{\circ}$ and the clearance between the two pieces is $1,5 \pm 0.5 \mathrm{~mm}$. Dimensions are represented in Figure 2.

Table 1: Specimens Preparation

\begin{tabular}{|c|c|}
\hline Specimens & Specifications \\
\hline A & Welded one time \\
\hline B & Welded second time \\
\hline C & Welded third time \\
\hline
\end{tabular}

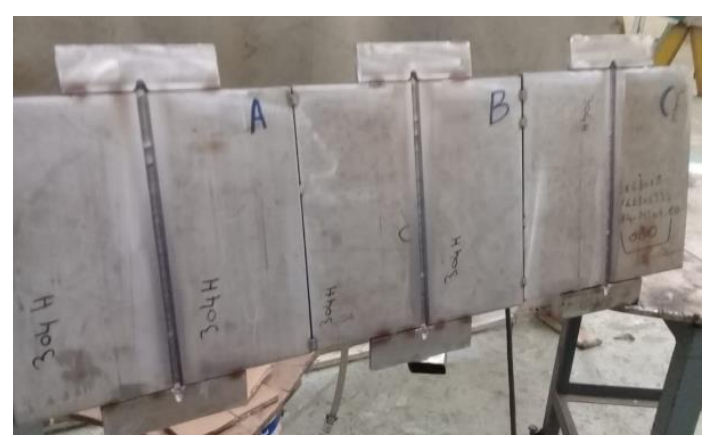

Figure 1: Specimens Welding Preparation.

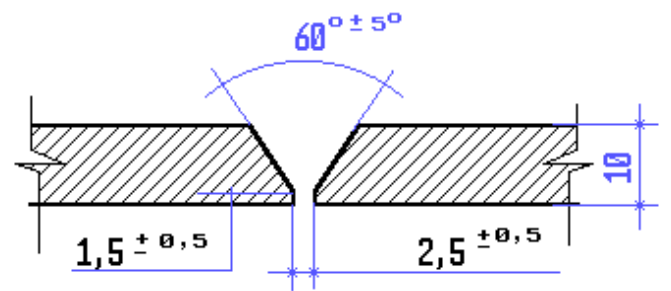

Figure 2: Welding Joint Preparation.

\subsection{Welding Parameters}

The methods of welding are prepared by seven passes are presented in Figure 2. 
The specifications of base metal 1 and 2 are represented in Table 2.

Figure 3 shows Preparation used by grinding and machine and the protection gas used is Argon 99,99\%[2].

The specimen will prepare at three parts, the first a specimen without any reparation, for the second specimen B with reparation of linear defect and for the third specimen $\mathrm{C}$ with the double reparation. The electrical parameters are shown in the Table 5 .

Table 2: Base Metal Specification

\begin{tabular}{|c|c|}
\hline Base Metal 1 & Base Metal 2 \\
\hline UNS S30403 & UNS S30403 \\
\hline Specification : SA-240 & Specification : SA-240 \\
\hline PN: 8 & PN: 8 \\
\hline Group N:1 & Group N:1 \\
\hline Thickness: $10 \mathrm{~mm}$ & Thickness: $10 \mathrm{~mm}$ \\
\hline
\end{tabular}

The chemical composition of base metal used of stainless steel $304 \mathrm{H}$ and filler metal are shown in the Table 3 and Table 4.

Table 3: Base Metal Chemical Composition

\begin{tabular}{|c|c|c|c|c|c|c|c|}
\hline Grad & C & Mn & Si & P & S & Cr & Ni \\
\hline 304H & 0.054 & 1,856 & 0.289 & 0.036 & 0.014 & 18.7 & 8.016 \\
\hline
\end{tabular}

Table 4: Filler Metal Chemical Composition

\begin{tabular}{|c|c|c|c|c|c|c|c|c|}
\hline Process & Grad & C & Mn & Si & P & S & Cr & Ni \\
\hline GTAW & ER308L & 0.025 & 1.8 & 0.45 & 0.02 & 0.02 & 20.2 & 10.0 \\
\hline SMAW & E308L-17 & 0.025 & 0.9 & 0.8 & 0.02 & 0.02 & 19.8 & 9.5 \\
\hline
\end{tabular}

Gas tungsten arc welding (GTAW) and Shielded metal arc welding (SMAW).

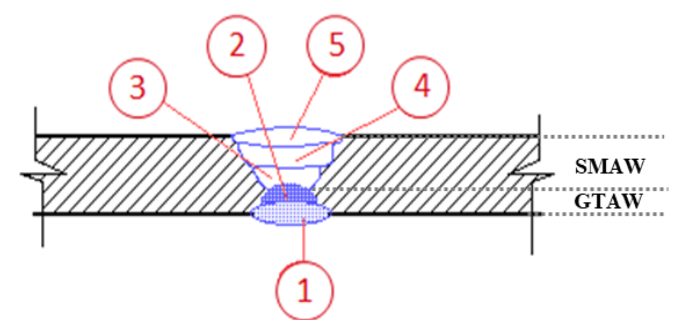

Figure 3: Welding Passes

Table 5: Preparation of the Specimens

\begin{tabular}{|c|c|}
\hline \multicolumn{2}{|r|}{ Electrical Parameters } \\
\hline Current & DC \\
\hline Polarity GTAW & Negative electrode \\
\hline Polarity SMAW & Positive electrode \\
\hline Amps & 1 :90A 2 :40A 3-4 :110A 5-6 :110A \\
\hline Volts & $1: 10,3 \mathrm{~V} 2: 10,2 \mathrm{~V} 3-4: 27,5 \mathrm{~V} 5-6: 27,5 \mathrm{~V}$ \\
\hline
\end{tabular}

\subsection{Non-Destructive Tests}

Three non-destructives tests used to assure the quality of the seam welding before starting the mechanical test, Visual test (VT), Penetrant test (PT), Radiographic test (RT).

Visual Inspection (VT) is a technique of verification of the weld with the naked eye. To be sure that there are no cracks, pits, surface-pores, undercut, under fill, missed joints, and other aspects of the weld using. 
Penetrant Test (PT) is method to detect surface-breaking discontinuities of the welded joint.

This method is used to detect surface defects invisible to the naked eye. It is based on the use of capillary properties of liquids on capillary penetration of special indicator liquids inside defects[3].

The specification of the penetrant product used is SHERWIN BABBCOO DP-55.

Radiographic Test (RT) used to detect discontinuities within the internal structure of welds. The advantage of this testing method is the ability to help establish the weld's internal quality without destroying the welded component.

The specifications used during the radiographic test are detailed in the Table 6 hereafter:

Table 6: Radiography Parameters

\begin{tabular}{|l|c|}
\hline \multicolumn{1}{|c|}{ Parameters } & Specifications \\
\hline Rayon gamma & IR 192 9,07 Ci \\
\hline Conditions of execution & EN ISO 17636-1 \\
\hline Material designation & Ir 192-AC633 \\
\hline Film type & D7/X \\
\hline IQI & ASTM/F \\
\hline
\end{tabular}

\subsection{Mechanical Tests}

\subsubsection{Tensile Test}

Tensile test used with laboratory equipment, for measurement of different tensile test values for the two species for each preparation A, B and C[4].

A tensile test is a physics experiment that allows determining the elastic behavior of a material and the measure the degree of breaking strength of a material, the specimen are prepared and tested according to EN ISO 6892-1.The tensile tests are prepared in the external laboratory and the result showed in the Table 7.

Table 7 shows the result of the tensile test are showed in the measurement table of yield strength $(\operatorname{Re}(\mathrm{N} / \mathrm{mm} 2))$, tensile strength $(\mathrm{Rm}(\mathrm{N} / \mathrm{mm} 2))$ and total elongation at failure:

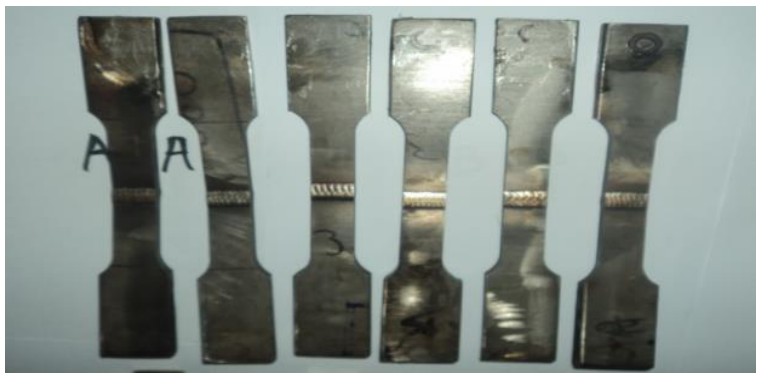

Figure 4: Preparation of the Tensile Test Specimens.

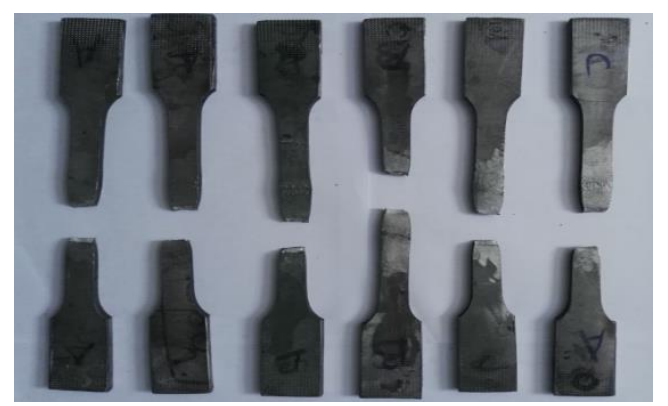

Figure 5: Result of the Tensile Test Specimens. 
Table 7: Tensile Test for Specimens A, B And C

\begin{tabular}{|c|c|c|c|}
\hline \multirow{2}{*}{ Tests } & Yield Strength $\left(\mathbf{R}_{\mathbf{e}}\left(\mathbf{N} / \mathbf{m m}^{\mathbf{2}}\right)\right)$ & Tensile Strength $\left(\mathbf{R}_{\mathbf{m}<}\left(\mathbf{N} / \mathbf{m m}^{2}\right)\right)$ & Total Elongation at Failure (\%) \\
\hline \multirow{2}{*}{ Specimen A } & 339 & 625 & 44 \\
\cline { 2 - 4 } & 345 & 632 & 46 \\
\hline \multirow{2}{*}{ Specimen B } & 355 & 641 & 50 \\
\cline { 2 - 4 } & 353 & 638 & 44,5 \\
\hline \multirow{2}{*}{ Specimen C } & 354 & 637 & 47 \\
\cline { 2 - 4 } & 350 & 636 & 47 \\
\hline
\end{tabular}

\subsubsection{Bend Test}

The bending test allowed determining the ability to deform by folding the welded joint. The samples are taken in the transversal direction to test the bending ability of the three samples, right and wrong[5].

The bend test has been done with the root and face of the weld in tension as shown in the Table 8 .

Table 8: Tensile Test for Specimens A, B and C

\begin{tabular}{|l|l|}
\hline \multicolumn{1}{|c|}{ Reference } & Observation \\
\hline Specimen A-1 & Transversal root bend correct without defects \\
\hline Specimen A-2 & Transversal face bend correct without defects \\
\hline Specimen B-1 & Transversal root bend correct without defects \\
\hline Specimen B-2 & Transversal face bend correct without defects \\
\hline Specimen C-1 & Transversal root bend correct without defects \\
\hline Specimen C-2 & Transversal face bend correct without defects \\
\hline
\end{tabular}

\subsubsection{Macrographic Examination}

The examination of a test specimen by the naked eye or under low magnification is used to reveal the welded joints. The surfaces were grinded and polished with the chemical attack used with Hcl. The result is shown in Fig. 6.

This method used for detection of defects presence or eventual defects could be created with the succession of the reparation especially for the specimen $\mathrm{C}$.

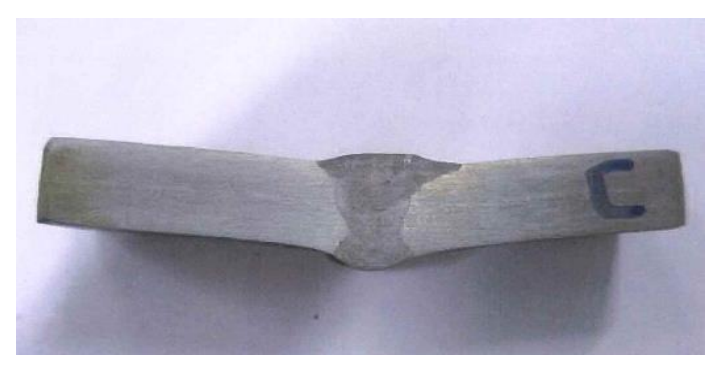

Figure 6: Result of the Tensile Test Specimens.

\subsection{Scanning Electron Microscope}

A scanning electron microscope (SEM) produces an image of a specimen by scanning it with a focused beam of electrons. This result have been done by an external laboratory in order to check the microstructure in the joint weld with heat affected zone, molten zone and base metal[6].

A result of the SEM is showed in the figures as follow, by showing the different zones of the weld with the magnification used is $100 \mu \mathrm{m}$. The references are shown in the Table 9.

The zones of the weld of the specimen with tow repairs are specified as followed zone MB, HAZ and FZ. The zones are 
represented in the Figure 7.

Table 9: SEM Zones

\begin{tabular}{|c|c|}
\hline SEM References & Zones \\
\hline C & Fusion zone (FZ) \\
\hline D & Heat affected zone (HAZ) \\
\hline A & Base metal (BM) \\
\hline
\end{tabular}

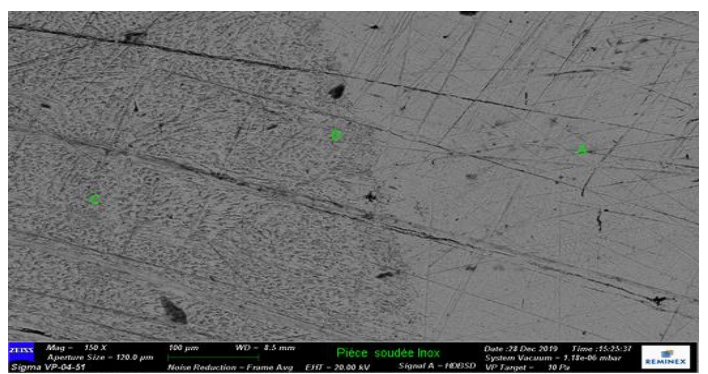

Figure 7: Weld Zones.

\subsubsection{Fusion Zone (FZ) Figures}

The Scanning electron micro scope result of fusion zone is shown in the Fig. 8 and Figure 9. The chemical composition is represented in the Table 10.

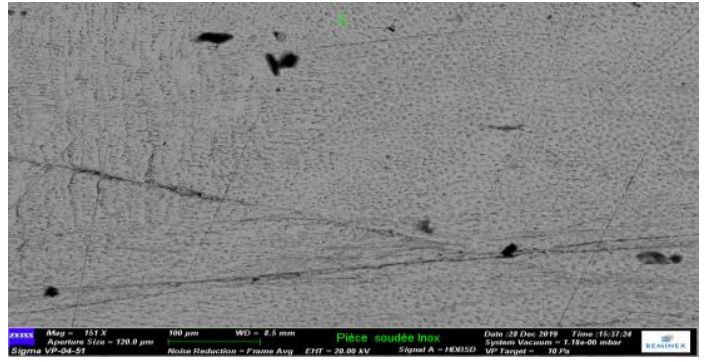

Figure 8: SEM of Fusion Zone (FZ).

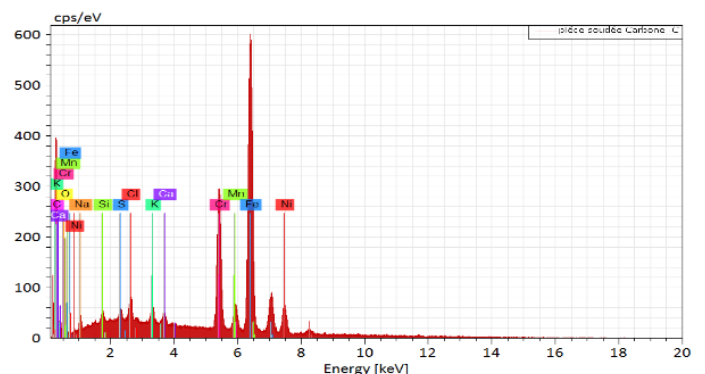

Figure 9: EDX Spectrum of Fusion Zone.

Table 10: Fusion Zone Chemical Composition 


\begin{tabular}{|l|l|l|l|l|l|}
$\begin{array}{l}\text { piéce soudée Carbone }-\mathrm{C} \\
\text { Element }\end{array}$ & At. No. $\begin{array}{c}\text { Mass } \\
{[\%]}\end{array}$ & $\begin{array}{l}\text { Mass Norm. Atom } \\
{[\%]}\end{array}$ & $\begin{array}{l}\text { abs. error [\%] } \\
\text { [1 sigma) }\end{array}$ \\
\hline Carbon & 6 & 36.58 & 36.58 & 68.26 & 1.92 \\
\hline Oxygen & 8 & 5.02 & 5.02 & 7.03 & 0.28 \\
\hline Sodium & 11 & 0.72 & 0.72 & 0.70 & 0.06 \\
\hline Potassium & 19 & 0.67 & 0.67 & 0.38 & 0.04 \\
\hline Calcium & 20 & 0.49 & 0.49 & 0.27 & 0.04 \\
\hline Chromium & 24 & 11.05 & 11.05 & 4.76 & 0.30 \\
\hline Manganese 25 & 0.90 & 0.90 & 0.37 & 0.05 \\
\hline Iron & 26 & 37.90 & 37.90 & 15.21 & 0.97 \\
\hline Nickel & 28 & 5.15 & 5.15 & 1.97 & 0.15 \\
\hline Silicon & 14 & 0.36 & 0.36 & 0.29 & 0.04 \\
\hline Sulfur & 16 & 0.32 & 0.32 & 0.22 & 0.03 \\
\hline Chlorine & 17 & 0.83 & 0.83 & 0.53 & 0.05 \\
\hline & & 100.00100 .00 & 100.00 & \\
\hline
\end{tabular}

\subsubsection{Heat Affected Zone (HAZ) Figures}

The Scanning electron microscope result of heat affected zone is shown in the Fig. 10 and Fig. 11. The chemical composition is represented in the Table 11.

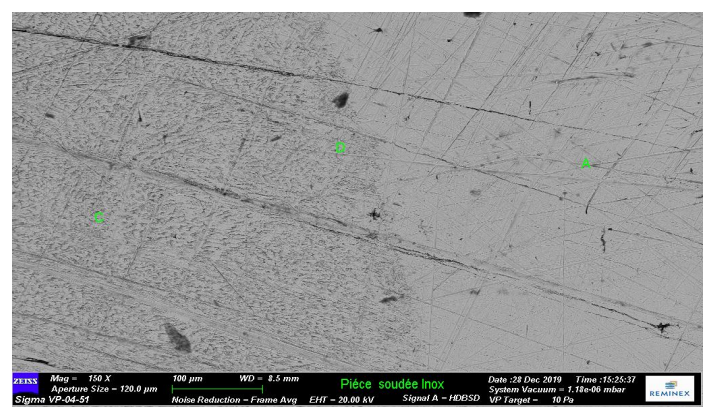

Figure 10: SEM of Heat Affected Zone (HAZ).

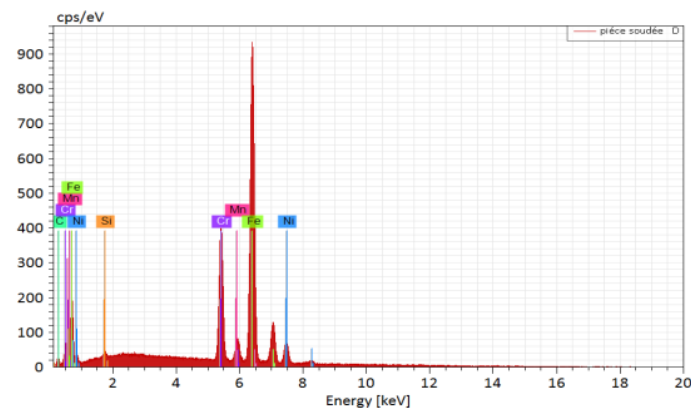

Figure 11: EDX Spectrum of Heat Affected Zone.

Table 11: Heat Affected Zone Chemical Composition piéce soudée $\mathrm{D}$

\begin{tabular}{|c|c|c|c|c|c|}
\hline Element & At. No. & $\begin{array}{l}\text { Mass } \\
{[\%]}\end{array}$ & $\begin{array}{l}\text { Mass Norm. } \\
{[\%]}\end{array}$ & $\begin{array}{l}\text { Atom } \\
{[\%]}\end{array}$ & $\begin{array}{l}\text { abs. error [\%] } \\
\text { (1 sigma) }\end{array}$ \\
\hline Carbon & 6 & 3.44 & 3.44 & 14.04 & 0.21 \\
\hline Chromium & 24 & 17.04 & 17.04 & 16.08 & 0.45 \\
\hline Manganese & 25 & 1.17 & 1.17 & 1.04 & 0.05 \\
\hline Iron & 26 & 70.22 & 70.22 & 61.69 & 1.79 \\
\hline Nickel & 28 & 7.74 & 7.74 & 6.47 & 0.22 \\
\hline Silicon & 14 & 0.39 & 0.39 & 0.67 & 0.04 \\
\hline
\end{tabular}

\subsubsection{Base Metal (BM) Figures}

The Scanning electron microscope result of base metal is shown in the Fig. 12 and Fig. 13. The chemical composition is represented in the Table 12. 


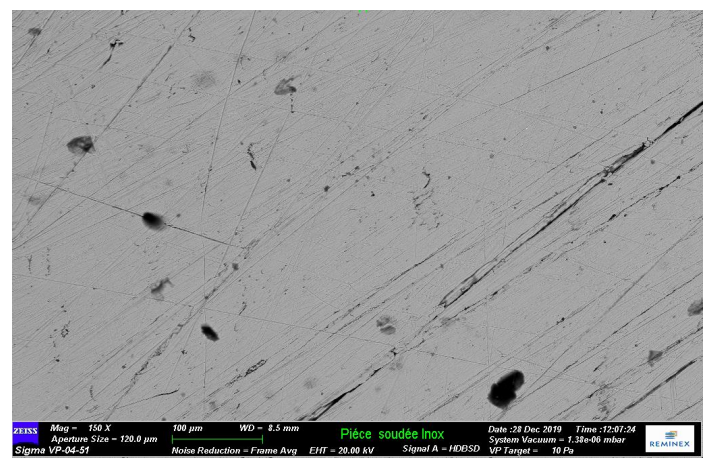

Figure 12: SEM of Base Metal (BM).

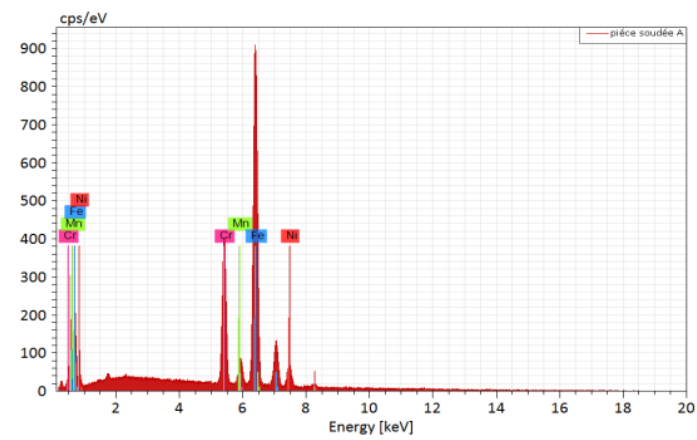

Figure 13: EDX Spectrum of Base Metal Zone.

Table 12: Base Metal Chemical Composition piéce soudée $A$

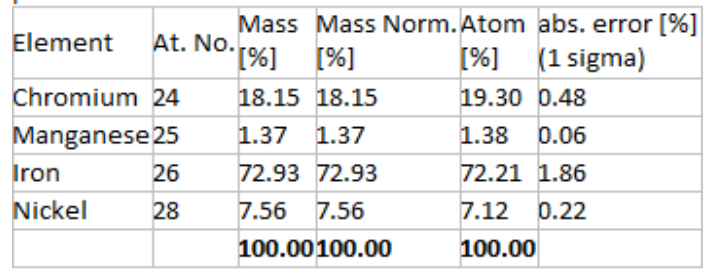

\section{RESULTS AND DISCUSSIONS}

Visual inspection shows that the spacemen have no unacceptable visual defects.

The penetrant test did not reveal any surface or opening defects, similar to the volume control by radiography for interior defects.

The results showed that the repairs did not generate any defect caused by heating during melting and cooling during solidification. The welding cycle multiplied to three[7].

This control was considered to eliminate all the faults to avoid any false indication on the results[2], [8].

This exemption from the defects demonstrated by non-destructive testing allows to go on to destructive tests.

Macrograph has demonstrated consistency and compatibility between the fusion zone and the heat affected area, which is explained by a perfect fusion of filler metal with the base metal joints. Also to validate the exemption from interior defects[9], [10].

The tensile test revealed that especially for the second repair and after the multiple welding cycle treatment demonstrated the acceptable values fell within the acceptance range by the international standard in force. The Yield strength, 
Tensile strength and Total elongation at failure respect the minimal values[7], [11].

The analysis of the coupon of the specimen A, B and C, shows that there is no unnatural deformation. The weld supports the consolidation during the bending test. This test reinforce all the test and controls have been done before[12], [13].

No defects in this austenitic stainless steel are occurs during and after the welding[10], for the solidification cracks it was avoided by using the appropriate filler metal according to Shaeffler diagram to have the impurities are absorbed in the ferrite percentage formed. The weld decay in this case of $304 \mathrm{H}$ and knife-line crack are avoided by the low-carbon percentage.

Grain growth is controlled by the surface energy at the boundary of the melt pool, the base metal is exposed by elevated temperature and sufficient time to observe the growth of the gains. As we move away from the melting boundary of the metal base, this part of the heat affected area receives less temperature and less time to favor coarse grain. The grains will have a smaller size than the gains in the melting boundaries. These gradually explain as one moves away from the pool's melting, the grain size decreases in the area affected by the heat[4][8]

\section{CONCLUSIONS}

The paper objective is the possibility confirmation of the multiple reparation in stainless steel of the weld.

The quality and the resistance of the weld after the second reparation confirm the defect exemption and the conformity of the standards and norms, of the values and parameters.

In other side the macroscopic and the microscopic examination highlight the quality of weld zones, and the different grains sizes between the fusion zone, heat affected zone and base metal.

The non-destructive test (NDT) shows that the welding with one tow and without reparation generates no unusual defect.

The tensile strength $\mathrm{Rm}[\mathrm{MPa}]$ respects the required value ofthe elongation and tensile strength $\mathrm{Rm}$ [MPa].

The stainless steel weld could be repaired for the second time.

The preparation and the specification used in this article showed a compliance to the requirement of the construction code about the mechanical proprieties[1], [2].

The work showed that for pressure vessels of the stainless it possible to weld till three time in the weld. These repairs do not generate any inconvenience in the quality of the weld if the welding procedure and the control are respected.

This study could help the manufacturer to avoid to change totally the material as shell, tubes and accessories by repairing the welds more than twice from the interior defects. The materials replacement costs will be avoided.

The future study will include more repairs and different grades and other analysis methods will be adopted.

\section{REFERENCES}

1. ASME, ASME Boilers and Pressure Vessel Code, 2019th ed. New York: Library of Congress Catalog Card Number: 56-3934, 2019.

2. S. Li et al., "Effect of repair welding on microstructure and mechanical properties of 7N01 aluminum alloy MIG welded joint," J. Manuf. Process., vol. 54, no. March, pp. 80-88, 2020, doi: 10.1016/j.jmapro.2020.03.009.

3. Duhan, R. A. V. I., and S. U. R. A. J. Choudhary. "Effect of different fluxes on hardness and microstructure of SS 304 in GTAW welding." International Journal of Mechanical Engineering 3.4 (2014): 1-8. 
4. V. Kumar, M. K. Parida, and O. P. Verma, "Evaluation of power sources and the effect of varying current in SMAW process," Int. J. Syst. Assur. Eng. Manag., vol. 11, no. 2, pp. 455-465, 2020, doi: 10.1007/s13198-019-00877-8.

5. Erfan, O. S. A. M. A., et al. "Erosion-corrosion behavior of AA 6066 aluminumalloy." Ijme 3 (2014): 15-24.

6. M. Yamazaki, T. Watanabe, H. Hongo, Y. Monma, and C. Tanaka, "Stress Rupture Factor for Butt Welded Joints of 304 Stainless Steel, ”J. Soc. Mater. Sci. Japan, vol. 41, no. 471, pp. 1779-1785, 1992, doi: 10.2472/jsms.41.1779.

7. R. Deraman and M. N. Berhan, Effect of cathodic hydrogen charging on mechanical properties of AISI 304 austenitic stainless steel welds, vol. 660. 2014.

A. E. Vladár and V.-D. Hodoroaba, Characterization of nanoparticles by scanning electron microscopy. 2019.

8. SALUJA, RATI, and K. M. Moeed. "Depiction of detrimentalmetallurgicaleffects in grade 304 austeniticstainlesssteel arc welds." International Journal of Mechanical and Production 8.6 (2018): 207-218.

9. D. Chauveau, "Review of NDT and process monitoring techniques usable to produce high-quality parts by welding or additive manufacturing," Weld. World, vol. 62, no. 5, pp. 1097-1118, 2018, doi: 10.1007/s40194-018-0609-3.

10. M. Balakrishnan, V. Balasubramanian, and G. Madhusudhan Reddy, "Microstructural analysis on ballistic tested armour steel joints fabricated using low hydrogen ferritic consumables for capping pass, ” Key Eng. Mater., vol. 812 KEM, pp. 1-8, 2019, doi: 10.4028/www.scientific.net/KEM.812.1.

11. RAGHAV, RAJNEESH, et al. "AN OPTIMIZING PARAMETERS OF ELECTRICAL DISCHARGE MACHINING ON STAINLESS STEEL 304 BY COPPER ALLOY TOOL USING RESPONSE SURFACE METHODOLOGY."International Journal of Mechanical and Production Engineering Research and Development(IJMPERD) Special Issue, Apr 2019, 90-95

12. M. Balakrishnan, V. Balasubramanian, G. Madhusuhan Reddy, and K. Sivakumar, "Effect of buttering and hardfacing on ballistic performance of shielded metal arc welded armour steel joints,” Mater. Des., vol. 32, no. 2, pp. 469-479, 2011, doi: 10.1016/j.matdes.2010.08.037.

13. P. Sharma and D. K. Dwivedi, "Comparative study of activated flux-GTAW and multipass-GTAW dissimilar P92 steel-304H ASS joints," Mater. Manuf. Process., vol. 34, no. 11, pp. 1195-1204, 2019, doi: 10.1080/10426914.2019.1605175.

14. D. V. Canle, J. Makinen, M. Gritsevich, A. Salmi, and E. Haggstrom, "Localization of millimeter size defects in a steel hemispherical shell," in IEEE International Ultrasonics Symposium, IUS, 2019, vol. 2019-Octob, pp. 1575-1578, doi: 10.1109/ULTSYM.2019.8925746.

15. T. Zhu, Y. Shi, S. Cui, and Y. Cui, "Recognition of Weld Penetration During K-TIG Welding Based on Acoustic and Visual Sensing," Sens. Imaging, vol. 20, no. 1, 2019, doi: 10.1007/s11220-018-0224-9.

16. Y. Xia, H. Dong, X. Hao, S. Li, P. Li, and G. Yang, "Microstructure evolution of TC4 titanium alloy/316L stainless steel dissimilar joint vacuum-brazed with Ti-Zr-Cu amorphous filler metal," Weld. World, vol. 63, no. 2, pp. 323-336, 2019, doi: 10.1007/s40194-019-00703-6. 